\title{
Psychophysiological processes of stress in chronic physical illness: a theoretical perspective
}

Nancy Kline Leidy RN PhD

Assistant Professor, College of Nursing, University of Anzona, Tucson Anzona

Judy G Ozbolt RN PhD

Professor and Associate Dean for Research, School of Nursing, University of Virginia,

Charlottesville Virginıa

and Mary Ann P Swain PhD

Professor, School of Nursing, Associate Vice President for Academic Affairs, Universtty of

Michigan Ann Arbor Michigan, USA

Accepted for publication 12 June 1989

KLINE LEIDY N OZBOLT J G \& SWAIN M A P (1990) Joumal of Advanced

Nursing 15, 478-486

Psychophysiological processes of stress in chronic physical illness: a theoretical perspective

This paper proposes a theoretical framework and conceptual model for clinicians and investigators working with people who have a chronic physical illness The framework is based upon nursing theory and classical propositions from psychology and physiology The major premise of the model is that individuals with limited psychosocial attributes and a preponderance of unmet basic needs are more likely to perceive events as threatening and expenence a maladaptive stress response, such as heightened symptoms and acute exacerbations of their illness Conversely, those with strong attributes and a perception of need satisfaction are more likely to view events as challenging, thus avoiding symptomatic discomfort and enhancing personal growth Implications for nursing practice and research are addressed

\section{INTRODUCTION}

A satısfying quality of life with feelings of well-being and opportunities for personal growth is a fundamental desire of all human beings Nurses are in a unique position to assist those with a chronic physical illness to higher levels of quality of life through purposeful interventions designed to minimize symptoms, reduce the frequency and intensity of acute exacerbations, and enhance psychosocial well-being The purpose of this paper is to propose a theoretical framework and conceptual model for nursing practice

Correspondence Dr Nancy Klne Lady College of Nurstng University of Anzona Tucson Anzona 85721 USA and research which describes the psychophysiological processes of stress that lead to personal growth or to acute exacerbations in people with a chronic physical illness

The foundation upon which this framework is built is the Erickson et al (1983) nursing theory of modelling and rolemodelling Bnefly, this nursing theory represents a synthesis of concepts from classical theories of stress adaptation (Cannon 1929, Engel 1968, Schmale 1972, Selye 1946), humanistic psychology (Maslow 1943, 1968), psychosocial and cognitive development (Enkson 1963, Piaget \& Inhelder 1969), object relations (Freud 1953-1974, Kernberg 1976), and attachment and loss (Bowlby 1973, 1980, 1982), among others Modelling in this theory, 
consists of the application of theoretical knowledge to client-specific information, including resources and limitations, in order to understand how the client views the world Role-modelling is the artful implementation of nursing interventions that are acceptable within the client's view of the world and lead to greater health (Enckson et al 1983)

This paper suggests that understanding the client's capacity for stress adaptation and intervening appropnately are central to effective nursing, that is, to nursing that promotes holistic health The paper will briefly review earlier theones of stress adaptation, describe how these are integrated in the modelling and role-modelling framework, and propose a revision of and an extension to the modelling and role-modelling theory that would seem to account more fully for observed phenomena, specifically with regard to persons with a chronic physical illness The paper will conclude with a presentation of the conceptual model and suggestions for further research

\section{STRESS ADAPTATION AS A CENTRAL CONCERN OF NURSING}

The purposes of nursing are to help clients restore, mantain or enhance their health and assist them in fulfilling their potential throughout life Some clients are sufficiently robust that they can achieve these goals with little more than skilled assistance from the nurse durng occasional bouts of illness In Maslow's (1943, 1968, 1970) terms, as incorporated into the theory of modelling and rolemodelling (Enckson et al 1983), these persons perceive that their basic needs are met and expenence a predominance of growth motivation, characterized by an attitude of challenge and a desire for self-actualization

Other clients, however, are more fragile Perceiving that their basic needs are not met, they expenience a predominance of deficiency motivation Dissatisfied with the state of affars and uncomfortable with feelings of threat, anxiety and tension, deficiency-motivated individuals utilize personal resources in an effort to gratify prevaling needs The strong desire for safety and secunity that accompanies the perception of threat can interfere with personal growth as the individual, afraid to take chances or to jeopardize any aspect of his uncertain situation, seeks to regain or maintain a familiar, safe environment rather than accept the challenge of new life expenences (Maslow 1968) These persons nisk being overwhelmed by the circumstances that contributed to the Illness, by the additional situations that arise from the illness and treatment and by crrcumstances external to the physical health problem itself

It is crucial that nurses understand and predict the adaptive capacities of their clients, and that they knowledgeably and deliberately select those interventions that will increase the adaptive capacties of those at nsk for being overwhelmed Only in this way can nurses provide appropriate, individualized care that leads effectively and economically to the goal of optimal, holistic health

\section{Stress as a physiologic phenomenon}

According to Selye (1976), stress is the non-specifically induced biological response of the body to any demand Thus, while the evocative agents may differ, the stress response itself, called the General Adaptation Syndrome (GAS), is manifested by a characteristic pattem of systemic biological change It is useful to think of this syndrome metaphorically, as a purposeful, coordinated effort among interdependent biological systems to defend the body against potential disease (Selye 1950, 1976) The ongoing GAS involves a three-phase process of adaptation and resistance consisting of an initial and acute alarm reaction followed by a stage of resistance and concluding in a stage of exhaustion Under this model, stressor characteristics do not play a predominant role in determining the nature of the stress response and the subsequent health outcome In fact, due to the influence of internal conditioning factors, what might generally be called 'a normally well-tolerated degree of stress' (Selye 1975) can become pathogenic, or distressing, for individuals with selectively vulnerable body systems Hence, while the GAS is comprised of commonly expenienced systemic characteristics which occur regardless of cause, unique individual sensitivities influence the intensity and progression of the GAS, as well as the location and extent of the more specific changes which may occur upon exposure to a stressor (Selye 1976, 1980)

Selye's theory of stress adaptation provides the foundation for several axioms that are central to the framework proposed in this paper First, chronic disease, defined in terms of the stress response, is a consequence of the interaction between a stressor, the individual's internal conditioning factors, and external conditioning influences Under this proposition, organ-specific and systemic changes take place in response to ongoing environmental and/or hereditary stressors Signs and symptoms of illness are expressions of the body's attempt to adapt to the ongoing stressors Second, individuals with a long-term illness are vulnerable to the effects of additional similar or dissımılar stressors These stressors can lead to a superimposed acute stress response which strains the already precanous organ system and may result in symptomatic discomfort and/or an acute exacerbation of the illness

Finally, unrelenting chronic stress and/or repeated exposure to acute stress expenences in situations involving 
a pre-existıng long-term illness will dımınish the individual's capacity for adaptation, resulting in distress with the associated organ system detenoration, progressive exhaustion and death (Kline Leidy, 1989) According to this scenano, a stressor becomes a distressor (and stress evolves into distress) as the individual's capacity to mobilize adaptation resources is exceeded (Enckson et al 1983)

It is important to recognize that the focus of Selye's work was primarily the impact of biophysical stressors and distressors on the body His research did not elaborate upon the nature of psychological stress, the role of cognition and appraisal in the onset or progression of the stress response or the affective concomitancies of the GAS

\section{Stress as a psychobiologic phenomenon}

An individual's intellectual and emotional responses to potentially stressful external and internal expenences are based upon an underlying cognitive and affective structure which Engel (1971a) called a 'map or plan of the environment represented in the central nervous system' According to this conceptualization, information is evaluated within the context of the person's pre-existing conscious and unconscious knowledge, expenences, perceived capabilities and feelings, that is, within what Enckson et al (1983) subsequently called the person's 'model of the world' Hence, it is the person's model of the world which gives the stimulus meaning, instigates a reaction and determines the form and intensity of the stress response, including the affective and behavioural manifestations

As the individual evaluates an environmental stimulus or life circumstance, a determination is made as to whether or not (or in what manner) the data are congruous with his/ her model of the world, and whether or not appropnate covert or overt responses are avallable ( 1 e exist within the person's response repertore and are accessible for employment) (Engel 1971b) In some circumstances, psychic manipulation may be sufficient to maintain or regain a dynamic steady state, while in others, the mental examination and testing of actions and consequences are followed by overt coping behaviours The latter situation involves a psychobıologic transformation from the individual's normal dynamic steady state to one of two distinct biological/ behavioural stress response alternatives a state of physiologic activation and anxiety or a situation of conservationwithdrawal and giving up (Engel 1968, Engel \& Reichsman 1956)

According to Engel, activation involves an affective state of anxiety accompanied by a sympathetic nervous system response (i e Cannon's physiologic fight-flight response) The purpose of activation is to induce coping behaviours which will act to resolve the situation through eradication of the problem, or attain proximity to a supportive other and/or distance from the perceived source of stress With intense levels of activation, the individual can become overwhelmed and begin to withdraw, leading to a biological/behavioural conservation-withdrawal response pattern The latter response, characterized by a predom!nance of parasympathetic activity, favours survival by minımızıng energy expenditure (Schmale 1972)

The biologic state of activation is accompanied by an affective response called the giving up-given up complex, characterized by feelings of helplessness or hopelessness, reduced self-image, loss of gratification or support in relationships or life roles, loss of continuity between past, present and future, and a reactivation of past experiences of helplessness or hopelessness (Engel 1968, Engel \& Schmale 1972) In some situations, the individual can proceed through the giving up-given up complex and return to a normal steady state Persistence or recurrence of the giving up-given up complex, however, is hypothesized to contribute to the emergence of disease in predisposed individuals (Engel 1968, Schmale 1969, 1972) Findings tend to support this proposition (Schmale 1972, Schmale \& Iker 1966, 1971) An important aspect of Engel's conceptualızation is that an external event or circumstance is not important in determining individual health outcome Rather, it is the individual's physiologic predisposition and how he or she responds to the circumstance that will determine the trajectory (Engel 1968)

\section{THE ADAPTIVE POTENTIAL ASSESSMENT MODEL: AN INTEGRATION}

The theory of modelling and role-modelling synthesizes the theoretical stress adaptation frameworks of Selye (1946, 1950, 1976, 1980) and Engel (1968) into the AdaptIve Potential Assessment Model (APAM), a holistic model which delineates two stress states (arousal and impoverishment) and one major non-stress state (equilibrium) comprised of two substates (maladaptive and adaptive equilibrium) It is a framework for describing and classifying an individual's potential to adapt to ongoing and forthcoming environmental stımuli through the mobilization of internal and external resources (Enckson \& Swain 1982) These environmental stimuli are classified as stressors or distressors Stimul are perceived as stressors, or challenges, when the individual perceives that she or he has sufficient resources to master the stimulı Stimuli are perceived as distressors, or threats, when the individual perceives that he or she may not or does not have sufficient resources for mastery 
The stress state of arousal occurs when an individual, perceiving the existence of a stressor, is able to mobilize his coping resources to contend with the situation It represents a coalescence of Cannon's fight-flight response, Selye's physıologic alarm reaction and Engel's state of activation and anxiety Arousal is clinically manifested by an elevation in systolic blood pressure, pulse and respiration, expressions of tension or anxiety without fatigue, sadness and depression, and elevated motor-sensory behaviour (Enckson \& Swain 1982) The state of arousal represents the existence of ample potential for the mobilization of coping resources, although the individual may not necessarily realize this potential (H C Enickson, personal communication, 28 February 1986)

The state in which an individual has diminished and/or depleted resources avalable for mobilization is called a state of impovenshment Theoretically, this state of distress is similar to Selye's stage of exhaustion and Engel's characterization of the conservation-withdrawal (Engel \& Schmale 1972) and giving up-given up (Engel 1968) response patterns Important clinical features of impoverishment include marked feelıngs of tension, anxiety, fatigue, sadness and depression $A$ reduction in motor activity is also apparent (Enckson \& Swain 1982) It has been proposed that feelings of helplessness and/or hopelessness are prominent characteristics of this stress state Because of the resource depletion, impoverished individuals are at nsk for experiencing the adverse physiological and psychological effects of distress (Enckson et al 1983)

A non-stress state of maladaptive equilibrium is a relatively steady state in which an individual copes with stressors in one subsystem by 'drawing energies' (Enckson et al 1983) from another subsystem or subsystems Under this framework, an individual expenencing a limitation in the biophysical domain (e $\mathrm{g}$ the existence of a chronic illness) must rely upon his psychological, cognitive and social resources in order to strengthen or adapt to the weakened system Clearly, an individual's capacity to adapt to situational or personal limitations in one system is strengthened by the existence of robust resources in alternative subsystems Similarly, the existence of limited resources in one system, together with depleted or limited resources in alternative systems, places the individual at a much greater risk for expenencing situations as distressful and suffering the adverse effects of distress

Finally, individuals in the non-stress state of adaptive equilibrium possess a good potential for the mobilization of resources and are in a state of minimal health risk (Enckson \& Swain 1982) Rather than employing their adaptive energies and resources to cope with life stress, individuals in adaptive equilibrium are able to use their resources for growth and health promotion, leaving no subsystem in jeopardy Clearly, this state implies the satisfaction of basic needs and a predominance of growthmotivated behaviour Within this context, health is seen as a state of 'dynamic equilibrium' (Erıckson et al 1983) among subsystems, a state of holistic well-being rather than merely the absence of disease The biophysical, psychological, social and cognitive aspects of an individual are a balanced integration which function as a single unit

\section{Predisposing conditions}

A person's adaptive potential may consist of any one of three states arousal, impoverishment or equilibrium, which is subdivided into adaptive equilibrium and maladaptive equilibrium The theory of modelling and rolemodelling not only describes these states of adaptive potential, but also delineates the conditions (1 e personal characteristics - resources and limitations) that give rise to a particular state For example, persons who possess relative satisfaction of basic needs and psychosocial attributes that reflect a favourable balance of sympathic strengths over antipathic limitations are more likely to perceive life circumstances as challenges, ie as stressors rather than as distressors, and to maintain a state of equilibnum Other theory-based characteristics hypothesized to promote a healthy state of equilibrium include cognitive complexity (ability to think abstractly, reason), attachment to need-satisfying objects and attainment of affiliatedindividuation (knowledge and experience of the self and others as separate but mutually caring individuals) In contrast, persons who have fewer resources, such as relative basic need deficits and/or a balance of antipathic limitations over sympathic strengths, are hypothesized to be at greater risk for perceiving environmental stimuli as threatening, $1 \mathrm{e}$ as distressors, and experiencing repeated states of arousal and/or persistent states of impoverishment

Not only do these conditions promote a tendency to view life circumstances as stressors or distressors and support particular states of adaptive potential, but it is also suggested that they are interrelated in ways that facilitate or inhibit health and development For exmple, satısfaction of basic needs is positively and reciprocally related to object attachment, cognitive complexity and the echievement of sympathic strengths Basic need satisfaction may also contribute to the tendency to view life crcumstances as stressors rather than distressors and the maintenance of dynamic equilibrium Cognitive complexity, achievement of sympathic strengths and object attachment are hypothesized to contribute to affiliated-individuation, which in turn 
promotes equilibrium and the perception of stimuli as stressors Conversely, relative deficits of basic needs promote and are promoted by object loss or isolation, impaired cognitive functioning and a relative balance of antipathic limitations over sympathic strengths, as well as contributing directly to the state of impoverishment and the tendency to view stimuli as distressors rather than as stressors Similarly, impaired cognition, a preponderance of antipathic limitations and object loss or isolation contribute to personal alienation, which, in turn, promotes the state of impoverishment and the view of stimuli as distressors (For a further exposition of these interrelationships, see Ozbolt \& Swain 1988)

Thus, according to the theory of modelling and rolemodelling, a person's adaptive state is the product of many forces acting in concert Under this paradigm, because the elements and relationships that give rise to states of equilibnum, arousal or impoverishment can be identified, nursing interventions to restore resources and promote adaptive potential can be defined and appropriately orchestrated

\section{EXPLOITING THE GROWTH POTENTIAL: A PROPOSED REVISION OF THE THEORY}

The theory of modelling and role-modelling offers a powerful intellectual tool for clinicians to plan and conduct interventions to promote adaptation and the attainment of holistic health potential Further consideration of the elements and relationships that contribute to adaptive potential, however, suggests a limitation in the conceptualization of the substates contained within adaptive equilibnum, particularly as they relate to people with a chronic physical illness According to the Enckson et al (1983) delineation of the APAM, individuals with a chronic physical illness are unable to achieve a state of adaptive equilibnum Because they must draw upon their psychological, social, spintual and cognitive resources in order to cope with their biophysical limitations, the maximum adaptive potential for these people is a state of maladaptive equilibrium, characterized by the taxing of coping resources This conceptualization is consistent with Selye's (1976) position that each individual has a finte reservorr of adaptation energy, with total depletion resulting in death

This conceptualization of maladaptive equilibrium, however, underestimates and undervalues the possibility of strengthening adaptive potential by supporting and faciltating need satisfaction, cognitive and psychosocial development, object attachment and affiliated-individuation Overcoming or compensating for a genetic or acquired limitation in one system (e $\mathrm{g}$ biophysical limitation in the case of chronic physical lliness) by relying upon resources avallable in alternative systems (psychological, cognitıve, social) should be considered adaptive, rather than maladaptive, provided the person is drawing upon resources that are increasing, as described in the relationships above, rather than decreasing An individual with chronic pulmonary disease, for example, might employ the psychosocial attributes of trust and hope to evaluate life circumstances as challenging, rather than threatening, thereby retaining the satisfaction of personal growth and dodging the ill-effects of distress In financial terms, the possession of substantial savings can permit one to exploit the interest, without reduang the principal Growth-motivated behaviour and self-actualizing expenences can contribute to one's resource principal which can, in turn, serve to buffer potentially stressful situations and enhance the interest avalable for daily stabilization and personal growth

\section{Compensatory equilibrium}

It is apparent that an individual with a chronic physical illness who perceives that basic needs are met, seeks to grow toward self-actualization and continues to build alternative resources may, in fact, be in a subtly different state of adaptive potential than one who is taxing resources in an attempt to maintain equilibrium The former could be described as compensating, while the latter is maladapting 'Maladaptive equilibrium' would still be an appropriate term to describe the person whose personal growth has stagnated, leaving finite (and indeed decreasing) resources to cope with demands in the obviously imparred and the less obviously limited dimensions of life

Thus, for purposes of the framework of chronic illness presented here, a third dimension of equilibrium is added to the APAM model This state of adaptive potential, compensatory equilibrium, is defined as a non-stress state characterized by irreversible limitations in one system with the concurrent use of resources from alternative systems to adapt to these limitations Individuals in compensatory equilibrium are at greater health risk than those in adaptive equilibrium due to restnctions which exist in a primary system They are differentiated from those in maladaptive equilibrium, however, by their greater resource potential, including the existence of healthy psychosocial attributes, a perception of basic need satisfaction and a predominance of growth motivation

This motivation of the theory of modelling and rolemodelling is more consistent with the theme of growth potential delineated in the theory In addition, it offers a more theoretically satisfying explanation for the clinical 
Figure 1 Psychophysiological processes of stress in people with a chronic physical illess

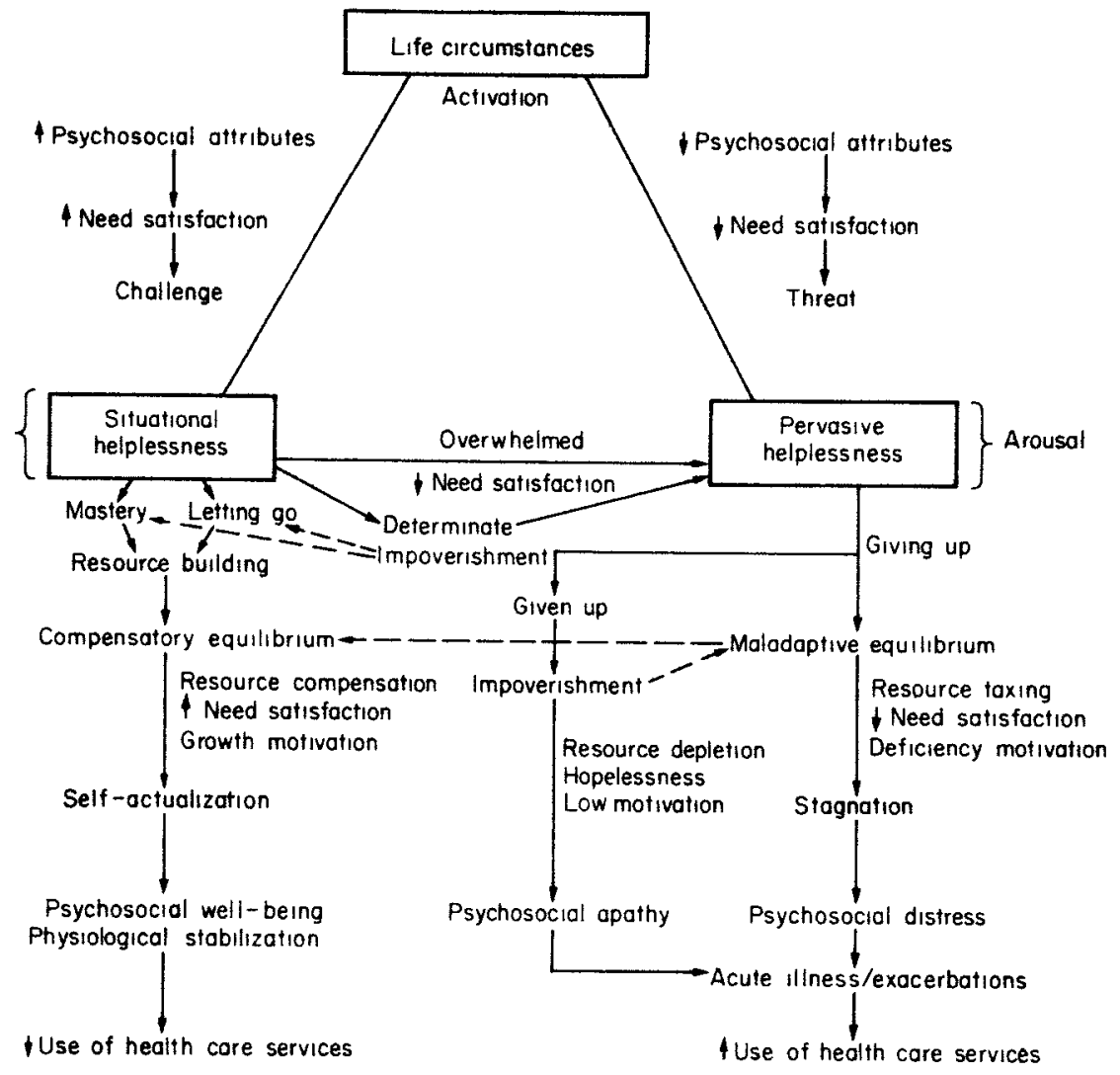

observation that some chronically ill persons appear overwhelmed and defeated by their lliness while others, with objectively similar levels of disease severity, manage to live fully and zestfully, with fewer exacerbations and illness-related limitations Early findings support the proposition that psychosocial attributes and basic need satisfaction allay perceptions of events as distressing and reduce symptomatic expenence in people with chronic obstructive pulmonary disease (Kline 1988) Further research is needed, however

SYNTHESIS: A CONCEPTUAL MODEL FOR EXPLAINING PSYCHOPHYSIOLOGICAL PROCESSES OF STRESS, COMPENSATION AND GROWTH IN PEOPLE WITH A CHRONIC PHYSICAL ILLNESS

In view of the need for greater attention to the health- and illness-promoting processes implicit in the theory of modelling and role-modelling, a conceptual model has been devised to delineate the processes that lead persons with chronic illness toward greater well-being and diminished use of health services or, alternately, toward more frequent exacerbations and increased use of health services (see Figure 1) While the process and outcome may exist as continua, a dichotomy is used for heuristic purposes The model is an outgrowth of the theory of modelling and role-modelling, incorporating three new concepts not previously articulated 'lettıng go', 'determinate impoverishment' and 'compensatory equilibrium' The latter was defined earlier in the paper and the others will be explained in the ensuing discussion

The model is based upon the premise that for any individual, life circumstances can lead to a marked level of arousal with concurrent feelings of helplessness The form of the instigating circumstance, the intensity and pervasiveness of the helplessness response and the psychophysiological outcome, however, are a function of the interaction which takes place between the event or situation and the individual's model of the world, that is, the personal meaning of the event for the individual and the internal and external resources avallable for dealing with the situation According to this framework, a perceptively similar circumstance may elicit an overwhelming response in one individual while prompting minumal reaction in another Instigating circumstances may include discrete events such as retrement, pregnancy, death of a spouse or loved one, change in jobs, moving or graduation. More subtle experiences such as public speaking, attending social events, having overnight guests, attempting new hobbies or sporting activities or driving a car may also initiate a 
response Instigating circumstances involve actual or threatened losses of valued persons (Including selfperception), places and/or things, or they may symbolize such a loss The term 'circumstance' is used to emphasize the subtle or unique experiences, beyond the common list of 'life events' (e g Holmes \& Rahe 1967) or 'daly hassles' (e g Kanner et al 1981) that may elicit a stress response in any chent, including those with a pre-existing chronic physical illness

Psychosocial attributes and pre-existing levels of need satisfaction are postulated to be internal resources which are central to the person's interactions with environmental stimulı Psychosocial attributes are defined as a positive balance of sympathic strengths to antipathic limitations, personal qualities and characteristics that evolve throughout life, as defined by Erikson's (1963) theory of development Because individuals with a preponderance of strengths and virtues are more likely to perceive that their basic needs are met, they are also more likely to accept the challenge of the circumstance and restrict the boundanes of their feelings of helplessness to the situation at hand Conversely, individuals with limiting attributes perceive a predominance of unmet needs prior to the circumstance, and thus tend to face the situation with a sense of threat and expenence a more pervasive feeling of helplessness

\section{Situational helplessness}

For individuals with strong psychosocial resources (healthy attributes and a sense of need satisfaction), feelings of situational helplessness will be followed by one of three alternative response modes In the first situation, the circumstance is appraised as a challenge, confronted and overcome, or mastered The crrcumstance thus serves as a positive life expenence which contributes to the individual's resource principal In the second response, the problem is evaluated as insurmountable and/or insignificant and is relinquished Because the individual has let go', this stressful expenence, like the first, evolves into an opportunity for resource building, personal growth and selfactualization In both situations, the individual acquires a clearer sense of one's self, resources and environment, and is able to resume a state of compensatory equilibrium, comprised of a comfortable level of need satisfaction and a predominance of growth-motivated behaviour Feelings of psychosocial well-being and physiological stabilization are important outcomes of these first two forms of adaptation to stress It is proposed that individuals with strong resources and a tendency toward situational helplessness and letting go also possess a differentral need for health care services to deal with their ongoing illness This is apparent in fewer and more well-defined requests for assistance

The third response mode for an individual whose antecedent attributes and correspondent feelings of need satısfaction are robust involves a distressing situation in which the individual is unable to surmount or relinquish the problem Under these circumstances, psychosocial attributes are insufficient to meet the demand, basic needs are no longer perceived as adequately satisfied and the incessant distressor becomes overwhelming for the individual This can lead to a state of determinate or circumscribed impovenshment charactenzed by perceptions of situational uncertainty, personal discontinuity and circumstantial hopelessness with diminished motivation for problem resolution Under extreme situations involving a persistent aversive or superimposed distressor, a circumscribed state of arousal or impovenshment can give way to a pervasive sense of helplessness which can evolve into a state of maladaptive equilibnum or impoverishment

With assistance from a significant other and/or nurse, the individual can move out of these three deletenous, resource-depleting states (determinate impovenshment, generalized impovenshment or maladaptive equilibrium) and into compensatory equilibrium The pathways of intervention and adaptation are represented by dashed lines in Figure 1 Thus, the nurse might help the person expenencing determinate impoverishment to master or 'let go' The person in generalized impoverishment will need support in order to move toward maladaptive equilibrium, e $\mathrm{g}$ meeting basic needs to promote object attachment and personal development, thereby restoring resources to cope with the problem and other aspects of life In addition, the person in maladaptive equilibrium will require further strengthening of resources to move towards personal growth and compensatory equilibrium

\section{Pervasive helplessness}

The person with limited psychosocial attributes and a pre-existing feeling of unmet basic needs is at nisk for responding to life circumstance with feelings of threat and a pervasive sense of helplessness Uncertain and yet unable to give up, the individual persists in the unsuccessful attempts to deal with the problem, or mourns a failure to satisfactonily resolve the situation This process is one of 'giving up', an acceptance of defeat and acknowledgement of one's own fecklessness that contrasts with the voluntary relinquishment of an unattainable goal, characterized as 'letting go' As resources are depleted, the feelings of helplessness give way to feelings of hopelessness and a sense of 
having 'given up' In this situation of generalized impoverishment, the individual lacks motivation to deal with the situation Thus, he or she is at risk for experiencing the adverse consequences of distress, including psychosocial apathy or withdrawal, and/or an acute illness or exacerbation of the chronic physical health problem By whatever route the client comes to the state of generalized impoverishment, the appropriate nursing intervention is to meet basic needs, knowing that this will promote development and restore resources, enabling the client to move first toward maladaptive and then toward compensatory equilibrium

An alternative to the state of generalized impoverishment is a situation in which the individual (without the aid of the nurse) is able to mobilize some resources in an attempt to adapt to the circumstance, attaining a stable, though maladaptive state of equilibrium Rather than letting go, however, the process of giving up is continued, taxing resources and placing already susceptible psychological, social and physiological subsystems in precanous balance Disturbed by pre-existing unmet needs, distressed over giving up and fearful of a perceived vulnerability, the individual is dominated by deficiency motivation Thus, a safe, secure, familiar environment is sought in an attempt to get basic needs met and avoid the distress associated with new life circumstances The stagnation which results from these fruitless efforts can aggravate the distress and isolation, while recurrent exposure to perceptively distressing experiences can lead to repeated and intense levels of arousal and impoverishment, and more rapid progression of disease It is postulated that for individuals with limited attributes and feelings of unmet basic needs, use of health care services is more frequent and characterized by vague requests for assistance

Nursing care for the chronically ill client with limited resources should be guided by mutually derived, attainable goals designed to build trust, promote control and develop and strengthen resources (Enckson et al 1983) By providing unconditional support and guidance, $1 \mathrm{e}$ rolemodelling, during potentially distressful circumstances, the nurse can facilitate successful problem resolution and help the client accumulate a set of positive expenences which will promote personal growth, facilitate the attainment and maintenance of compensatory equilibnum and further progression toward self-actualization

\section{TESTING THE MODEL}

Research has already begun to test aspects of the model One study, addressed earlier, found that psychosocial attributes and perceived need satisfaction were not only related to one another, but were related, directly or indirectly, to perceived stress and symptomatic expenence in people with chronic obstructive pulmonary disease (Kline 1988) Additional quantitative and qualitative studies are needed to examine other aspects of the model For example, how can situational helplessness be clinically differentiated from pervasıve helplessness? Similarly, how can giving up be distinguished from given up? From letting go? Do persons with strong psychosocial resources who confront a stressor and master it or let go indeed acquire a clearer sense of self, resources and environment? In clinical settings, are persons with limited psychosocial attributes and a preexisting feeling of unmet basic needs more likely to perceive the demands of their illness and treatment as distressful and to respond by giving up and moving into generalized impoverishment? How is this expressed affectively, behaviourally, physiologically? In a broader sense, clinical trials must be conducted to test the efficacy of specific nursing interventions to reduce acute illness and the need for acute care services For example, interventions designed to meet needs, build trust, promote control and develop and strengthen resources should help clients move from impoverishment and maladaptive equilibrium toward compensatory equilibrium, thus promoting physılogical stabilization (Erickson et al 1983)

The proposed conceptual model is an outgrowth of the nursing theory of modelling and role-modelling To the degree that it is empincally validated, the model offers nurses a way to understand client experiences, predict outcomes and choose appropriate nursing interventions Further, because of its nch theoretical orientation and its potential utılity in nursing practice, the model offers an exciting framework for nursing research

\section{CONCLUSION}

The purpose of this paper was to propose a theoretical framework for nursing practice and research pertaining to clients with a chronic physical illness The nursing theory of modelling and role-modelling provided the foundation for this work The psychophysiological processes of stress in people with a chronic physical illness were described, predicting outcomes in terms of psychosocial status and the use of health care services The conceptual model proposed here is easily adapted to healthy persons, with acute illness rather than exacerbations an eventual outcome of maladaptation or impoverishment, and equilibrium rather than compensatory equilibrium the desired non-stress state conducive to holistic health and personal growth If further research continues to support the model, its incorporation into nursing practice should improve the processes and the outcomes of nursing practice 


\section{Acknowledgements}

The authors gratefully acknowledge Helen C Enckson RN, $\mathrm{PhD}$ of the University of Texas at Austin for her comments on an earlier version of this paper The creation of this theoretical framework and conceptual model was supported, in part, by a National Research Service Award (Grant F-5-F31-NU05758) and a Professional Nurse Traineeship (Grant 2A11-NU00222), Department of Health and Human Services, United States Public Health Service

\section{References}

Bowlby J (1973) Attachment and Loss Vol II Separation, Anxiety and Anger Basic Books, New York

Bowlby J (1980) Attachment and Loss Vol III Loss Sadness and Depression Basic Books, New York

Bowlby J (1982) Attachment and Loss Vol I Attachment 2nd edn Basic Books, New York

Cannon W B (1929) Bodily Changes in Pain, Hunger Fear and Rage An Account of Recent Researches into the Function of Emotional Exctement Appleton, New York

Engel $G$ (1968) A life setting conducive to illness the giving up-given up complex Annals of Internal Medicine 69(20). 293-300

Engel G (1971a) Attachment behavior object relations and the dynamic-economic points of view critical review of Bowlby's Attachment and Loss Intemational Joumal of Psycho-Analysis 52, 183-196

Engel G (1971b) Sudden and rapid death during psychological stress Folklore or wisdom? Annals of Internal Medicine 74, $771-782$

Engel G (1978) Psychologic stress, vasodepressor (vasovagal) syncope, and sudden death Annals of Intemal Medicine 69, 403-412

Engel G \& Reichsman G (1956) Spontaneous and expenmentally induced depression in an infant with a gastric fistula Joumal of the American Psychoanalysts Association 4, 428-452

Engel G \& Schmale A H (1972) Conservation-withdrawal a primary regulatory process for organismic homeostasis Phystology, Emotion and Psychosomatics Ciba Foundation Symposium 8 Associated Scientific Publisher, Amsterdam, pp 57-85

Enckson H \& Swain M A (1982) A model for assessing potential adaptation to stress Research in Nursing and Health 5, 93-101

Erıckson H, Tomlin E \& Swain M A (1983) Modeling and RoleModeling $A$ Theory and Paradigm for Nursing Prentice-Hall, New Jersey

Erikson E (1963) Childhood and Soctety (rev edn) WW Norton, New York.
Erikson E (1982) The Life Cycle Completed WW Norton, New York

Freud S (1953-1974) The Standard Edition of the Complete Psychological Writings Hogarth, London

Holmes T \& Rahe R H (1967) The Social Readjustment Rating Scale Joumal of Psychosomatic Research 11, 213-218

Kanner A , Coyne J. Schaefer C \& Lazarus R (1981) Comparison of two modes of stress measurement daly hassles and uplifts versus major life events Joumal of Behavioral Medicine 4, 1-39

Kemberg $O$ (1976) Object Relations Theory and Clinical Psychoanalysis Jason Aranson, New York

Kline NW (1988) Psychophysiological processes of stress in people with a chronic physical illness (Doctoral dissertation, University of Michigan, 1988) Dissertation Abstracts International 49(6), 2129-B

Kline Leidy $M$ (1989) A physıologic analysis of stress and chronic illness Joumal of Advanced Nursing 14(10), 868-876

Maslow A (1943) A theory of human motivation Psychological Review 50, 370-396

Maslow A (1968) Toward a Psychology of Being Van Nostrand Reınhold, New York

Maslow A (1970) Motivation and Personality Harper \& Row, New York

Ozbolt J \& Swain MA (1988) Representing a nursing knowledge base for a decision support system in prolog In Proceedings of the 12th Annual Symposium on Computer Applications in Medical Care (Greenes R A ed), IEEE Computer Society Press, Washington DC, pp 119-125

Piaget I \& Inhelder B (1969) The Psychology of the Child Basic Books, New York

Schmale A (1969) Importance of life setting for disease onset Modern Treatment 6, 643-655

Schmale A (1972) Giving up as a final common pathway to changes in health Adoances in Psychosomatic Medicine 8, 20-40

Schmale A \& Iker H (1966) The affect of hopelessness and the development of cancer identification of utenne cervical cancer in women with atypical cytology Psychosomatic Medicine 28, 714-721

Schmale A \& Iker H (1971) Hopelessness as a predictor of cervical cancer Social Sctence and Medicine 5, 95-100

Selye $H$ (1946) The general adaptation syndrome and the diseases of adaptation Joumal of Clinical Endocrinology 6, $117-230$

Selye H (1950) Stress Acta, Montreal

Selye H (1975) Confusion and controversy in the stress field Journal of Human Stress 1, 37-44

Selye H (1976) The Stress of Life McGraw-Hill, New York

Selye H (ed) (1980) Selye's Guide to Stress Research Vol 1 Van Nostrand Remhold, London 
This document is a scanned copy of a printed document. No warranty is given about the accuracy of the copy. Users should refer to the original published version of the material. 